\title{
Benzothiadiazides Inhibit Rapid Glutamate Receptor Desensitization and Enhance Glutamatergic Synaptic Currents
}

\author{
Kelvin A. Yamada ${ }^{1}$ and Cha-Min Tang ${ }^{2}$ \\ 'The Departments of Neurology and Pediatrics, Washington University School of Medicine, St. Louis, Missouri 63110 and \\ ${ }^{2}$ The Department of Neurology, University of Maryland School of Medicine, Baltimore, Maryland 21201
}

\begin{abstract}
A distinctive characteristic of the AMPA subset of glutamate receptor channels is their remarkably rapid desensitization. A family of compounds, the benzothiadiazides, is described here that potently inhibit rapid glutamate receptor desensitization. The structure-activity relationships of these compounds are examined and the actions of cyclothiazide (CYZ), the most potent of these compounds, are described in detail. At the macroscopic level $C Y Z$ reduced rapid desensitization, enhancing the steady-state and peak current produced by $1 \mathrm{~mm}$ quisqualate with $\mathrm{EC}_{50}$ values of 14 and $12 \mu \mathrm{M}$, respectively, and shifted the quisqualate peak current concentration-response relation to the left. The slight outward rectification of the steady-state quisqualate current-voltage relationship was reduced by CYZ. At the microscopic level CYZ caused glutamate to induce long bursts of channel openings, and greatly increased the number of repeated openings. At $10 \mu \mathrm{M} \mathrm{CYZ}$ did not have measurable effects on the fast component of deactivation nor did it have statistically significant effects on the distribution of the faster components of glutamate-induced burst duration. In contrast, 10 $\mu \mathrm{M} C Y Z$ increased the amplitude and significantly prolonged the duration of the spontaneous miniature EPSCs. The identification and characterization of this new family of gating modifiers may further facilitate the investigation into the mechanisms underlying rapid glutamate receptor desensitization and the physiological roles that it may serve.

[Key words: AMPA receptor, spontaneous miniature synaptic currents, EPSC, cultured hippocampal neurons, voltage clamp, cyclothiazide]
\end{abstract}

Postsynaptic glutamate receptor channels are important molecular entities mediating excitatory synaptic transmission throughout the vertebrate CNS (Mayer and Westbrook, 1987).

\footnotetext{
Received Sept. 21, 1992; revised Mar. 8, 1993; accepted Mar. 18, 1993.

We thank Steve Rothman and Dick Horn for many helpful discussions and suggestions, Qing-Yao Shi for helping with the single-channel recordings, and Nancy Lancaster for preparing cell cultures. We are indebted to Chuck F. Zorumski, Steve Mennerick, Jiaxin Que, and Liu Lin Thio for helpful discussions and for providing software for detecting and analyzing miniature synaptic events. We thank the Lily Research Laboratories for generously supplying cyclothiazide for our experiments, Bristol-Myers-Squibb Company for providing hydroflumethazide, Schering Corporation for providing trichlormethiazide, and Lederle Laboratories for providing quinethazone. This work was supported by National Institutes of Health Grants NS 01443 (K.A.Y.), NS 28158 (C.-M.T.), NS 19988 (Steven M. Rothman), a Klingenslein Foundation Award (to C.-M.T.), and a grant from the Whitaker Foundation.

Correspondence should be addressed to Kelvin A. Yamada, M.D., Departments of Neurology and Pediatrics, Washington University School of Medicine, 660 South Euclid Avenue, St. Louis, Missouri 63110.
}

Copyright (C) 1993 Society for Neuroscience $0270-6474 / 93 / 133904-12 \$ 05.00 / 0$
These channels have been divided into two major categories, the NMDA and the non-NMDA receptor channels. NMDA receptor channels have been shown to mediate the slow EPSCs in central neurons (Forsythe and Westbrook, 1988) and nonNMDA receptor channels have been shown to mediate the fast EPSCs (Hestrin et al., 1990). While step applications of glutamate evoke slow decremental current responses from NMDA receptor channels (Ascher et al., 1988; Mayer et al., 1989), similar stimuli evoke rapidly decaying current responses from nonNMDA receptor channels (Kiskin et al., 1986; Tang et al., 1989; Trussell and Fischbach, 1989; Thio et al., 1991). The time dependent decay of the current response to a constant agonist concentration is known as desensitization (Thesleff, 1955). The speed and extent of rapid non-NMDA desensitization are unparalleled among transmitter-gated receptor channels. Identifying the physiological role, if any, for this rapid desensitization remains an important unanswered question. Does rapid desensitization protect against glutamate-mediated excitotoxicity? Is it a means to modulate synaptic efficacy? Does rapid desensitization participate in determining the amplitude and the duration of the fast EPSC? The availability of gating modifiers for non-NMDA glutamate receptor channels that potently, reversibly, and selectively inhibit rapid desensitization may provide the opportunity to address these questions.

A number of agents have recently been reported to reduce rapid glutamate receptor desensitization. These include ConA, WGA, and aniracetam. Con A and WGA are plant lectins, proteins with high-affinity binding sites for polysaccharides. These lectins, however, also have a number of different actions (Lin and Levitan, 1991). Their inhibition of desensitization requires incubation for a period of time and is essentially irreversible (Thio et al., 1992b). WGA prolongs the burst duration of nonNMDA channels and increases the frequency of bursts in hippocampal neurons (Thio et al., 1992b). The effects of ConA on the single-channel properties of central neurons have not yet been reported. Different effects upon the magnitude and time course of the fast EPSC have been reported for WGA and ConA (Vyklicky et al., 1991; Thio et al., 1992a, 1993). Aniracetam is a low-molecular-weight nootropic agent that reversibly inhibits rapid desensitization (Isaacson and Nicoll, 1991; Tang et al., 1991; Vyklicky et al., 1991). It is a relatively weak inhibitor of desensitization. Furthermore, aniracetam also slows the closing rate of the non-NMDA channels upon rapid removal of glutamate (Tang et al., 1991).

Recently, diazoxide was found to be a potent and reversible gating modifier for AMPA-type non-NMDA channels (Yamada and Rothman, 1992). Subsequent investigation extended this 
discovery to a family of related but more potent gating modifiers, all of which are benzothiadiazides. Figure 1 illustrates their basic structure. This study examined the effects of several benzothiadiazides on glutamate- and quisqualate-activated whole-cell currents recorded from patch-clamped hippocampal neurons. Cyclothiazide (CYZ), the most potent of the benzothiadiazides tested, was most extensively studied. The effects of CYZ on the fast gating kinetics of the non-NMDA channels and on the spontaneous miniature EPSCs (mEPSCs) were examined in detail. The results indicate that certain benzothiadiazides potently, reversibly, and in a concentration-dependent fashion reduce rapid glutamate receptor desensitization. The data further suggest that desensitization contributes, in part, to determining the peak amplitude and duration of the fast EPSC.

\section{Materials and Methods}

Cell culture preparation. For whole-cell recordings, rat hippocampal cell cultures were prepared from postnatal rats (Yamada and Rothman, 1992) and recording was performed within the first $17 \mathrm{~d}$ after plating. For excised outside-out patch recordings and the cxpcriment in Figurc 10, hippocampal cell cultures were prepared from prenatal rats (Tang et al., 1991). Recordings of channel events shown in Figure 7 were obtained from a neuron derived from the NT2 human cell line induced to express glutamate receptor channels (Younkin et al., 1993).

All drugs and reagents were purchased from Sigma (St. Louis, MO) with the following exceptions: quisqualate was purchased from Research Biochemical (Natick, MA), MK-801 was provided by Merck, Sharp and Dohme (Rahway, N.J), 6-cyano-7-dinitroquinoxaline-2,3-dione (CNQX) was purchased from Tocris Neuramin (Cambridge, England), cyclothiazide was provided by Lilly Research Laboratories (Indianapolis, IN), hydroflumethazide (HFZ) was provided by Bristol-Myers Squibb Company (Evansville, IN), trichlormethiazide (TMZ) was provided by Schering Corporation (Kenilworth, $\mathrm{NJ}$ ), and quinethazone was provided by Lederle Laboratories (Pearl River, NY).

Electrophysiology. For whole-cell recording, growth medium was replaced with an extracellular recording solution containing (in $\mathrm{mM}$ ) 140 $\mathrm{NaCl}, 3 \mathrm{KCl}, 6 \mathrm{MgCl}_{2}, 6 \mathrm{CaCl}_{2}, 10 \mathrm{HEPES}, 5.5$ glucose, and $0.0006-$ 0.001 tetrodotoxin; $20 \mu \mathrm{M} \mathrm{MK}-801$ and $20 \mu \mathrm{M}$ bicuculline were added to block NMDA and GABA receptor channels (except for experiments represented in Fig. 5); in addition, $100 \mu \mathrm{M} \mathrm{CdCl}_{2}$ was added in experiments studying spontaneous miniature synaptic currents and currentvoltage relationships. The $\mathrm{pH}$ was 7.3 . Whole-cell patch pipettes were filled with an intracellular recording solution containing (in $\mathrm{mM}$ ) 138 potassium isethionate, $2 \mathrm{KCl}, 10 \mathrm{HEPES}, 1.1 \mathrm{EGTA}, 4$ glucose, and 2 $\mathrm{Mg}-\mathrm{ATP}$, pH 7.3; these electrodes (5-7 M $\Omega$ DC resistance) were connected to commercial patch amplifiers to achieve whole-cell recording (Hamill et al., 1981). When recording synaptic currents or producing current-voltage relationships, $130 \mathrm{mM} \mathrm{CsCl}_{2}$ and $10 \mathrm{~mm}$ tetraethylammonium chloride replaced the potassium salts. Data were digitized at $1-10 \mathrm{kHz}$ and stored on disk for later analysis. For recordings from excised outside-out patches the external solution consisted of (in $\mathrm{mm}$ ) $150 \mathrm{NaCl}, 3 \mathrm{KCl}, 2 \mathrm{CaCl}_{2}, 1 \mathrm{MgCl}_{2}, 10 \mathrm{HEPES}, 100 \mu \mathrm{M}$ aminophosphonovalerate, $100 \mu \mathrm{M}$ picrotoxin, and $1 \mu \mathrm{M}$ TTX; buffered to $\mathrm{pH} 7.3$. Internal pipette solution consisted of (in mM) $140 \mathrm{CsMeSO}_{4}, 5 \mathrm{Na}-$ BAPTA, $1 \mathrm{MgCl}_{2}, 2 \mathrm{CaCl}_{2}$, and 10 HEPES; buffered to $\mathrm{pH} 7.3$. Thickwalled hard borosilicate glass (Word Precision Instruments 1B150F-6) were pulled to resistance of 50-100 $\mathrm{M} \Omega$ for excised patch recordings. Electrodes were heavily coated with Sylgard (Dow Corning 184). Currents were acquired using a Dagan 3900 integrating amplifier, filtered at $2 \mathrm{kHz}$, sampled at $5 \mathrm{kHz}$, and stored on disk.

Whole-cell currents were obtained by applying agonists to neurons voltage clamped at $-60 \mathrm{mV}$. Discontinuous single-electrode voltage clamp (dSEVC) at a sampling rate of $10-10.5 \mathrm{kHz}$ and sampling interval $30 \%$ of the duty cycle was used to eliminate the contribution of series resistance error. Continuous monitoring of the voltage sampling on a second oscilloscope was used in dSEVC mode, and adjustments were made to ensure return of the membrane potential to the command potential prior to the current injection cycle. Usually no adjustments were required. Some whole-cell current data (see Figs. $4 B, 5$ ) were obtained using continuous single-electrode voltage-clamp (cSFVC). Rapid, whole-cell, agonist application was accomplished by placing various agonist preparations in reservoirs connected to a solenoid valve that
BENZOTHIADIAZIDE DRUGS<smiles>CC1=Nc2ccc(Cl)cc2[S+](=O)(=O)N1</smiles>

DIAZOXIDE<smiles>[B]N1Nc2cc(S(=O)(=O)O)c(P)cc2S1(=O)=O</smiles>

BENZOTHIADIAZIDE STRUCTURE<smiles>CS(=O)(=O)c1cc2c(cc1Cl)NC(C1CC3C=CC1C3)N(S(C)(=O)=O)S2</smiles>

CYCLOTHIAZIDE

BENZOTHIADIAZIDE-RELATED DRUGS

QUNNETHAZONE<smiles>CCC1NC(=O)c2cc([S+]([O])(=O)=O)c(Cl)cc2N1</smiles>

SULFADIAZINE

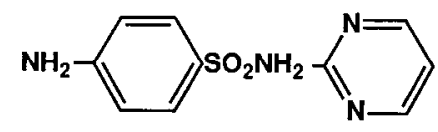

Figure 1. Structures of benzothiadiazide and related compounds mentioned in this report. Diazoxide was the compound initially identified with actions against rapid glutamate desensitization. Substitutions at the $R_{3}$ and $R_{6}$ positions distinguish the different benzothiadiazide analogs reported here and are listed in Table 1. CYZ was studied most extensively.

opened and closed to allow flow by gravity according to computer-driven protocols. Agonist preparations were released through a tapered-tip largebore glass pipette $(\approx 300 \mu \mathrm{m}$ i.d.) attached directly to the solenoid valve. To test the effects of drugs (such as CYZ) on agonist responses, agonist responses were recorded in control buffer and after application of experimental drugs. The steady-state current was defined as the average current amplitude of a $20 \mathrm{msec}$ interval at the end of the agonist application interval. Quisqualate and CYZ concentration-response curves were generated by normalizing the peak and/or steady-state quisqualate responses from different cells to the response to $1 \mathrm{~mm}$ quisqualate and plotting the data as a percentage of the $1 \mathrm{~mm}$ response. Smooth curves were fitted through the data using a four-parameter logistic fit (sIGMAPLOT, Jandel Scientific, Corte Madera, CA).

Steady-state quisqualate current-voltage relationships were obtained using dSEVC to eliminate series resistance error. The voltage step protocol consisted of sequence of fifteen 45 -msec-long steps to command potentials at $10 \mathrm{mV}$ increments between -90 and $+50 \mathrm{mV}$. This sequence was repeated five times and averaged in control buffer, in buffer containing $15 \mu \mathrm{M}$ quisqualate, and in buffer containing $15 \mu \mathrm{M}$ quisqualate plus $1 \mu \mathrm{M} \mathrm{CYZ}$. Leak subtraction was accomplished by subtracting the currents obtained from the voltage step protocol in control buffer from both the quisqualate and quisqualate plus CYZ currents. The steadystate current for each voltage step was the average value of the current over a $20 \mathrm{msec}$ interval near the end of the $45 \mathrm{msec}$ voltage step.

Excised patch currents were obtained by applying agonists to outside- 
Figure 2. The effect of $\mathrm{CYZ}$ on quisqualate-activated currents. $A, \mathrm{CYZ}$ at $0.3-100 \mu \mathrm{M}$ reduces desensitization from quisqualate activated whole-cell currents in a concentration-dependent fashion. Traces are from a representative postnatal hippocampal neuron. The holding potential was $-60 \mathrm{mV} . B$, Current-voltage relationships of the steadystate component of quisqualate activated current without (solid circles) and with (open triangles) $1 \mu \mathrm{M} \mathrm{CYZ.} \mathrm{CYZ}$ increased the slope conductance while the reversal potential remained unchanged near $0 \mathrm{mV}$. The control curve shows a slight degree of outward rectification that is also reduced by CYZ. $C$ and $D$, Concentration-response curves for enhancement of steady-state $(C)$, and peak $(D)$ currents activated by 1 mm quisqualate. In $C$ and $D$, the numbers in parentheses are the numbers of measurements for that concentration; 10 neurons like the example in $A$ were used to generate these data (error bars are SEM). The smooth lines were fitted through the data as described in Materials and Methods. The $\mathrm{EC}_{50}$ obtained from the curve fit was $14 \mu \mathrm{M}$ for $C$ and $12 \mu \mathrm{M}$ for $D$. At $100 \mu \mathrm{M}$ CYZ there was about a fourfold increase in the peak current (see also Fig. 3) and a 400-fold increase in the steady-state current when compared to the control response.

A
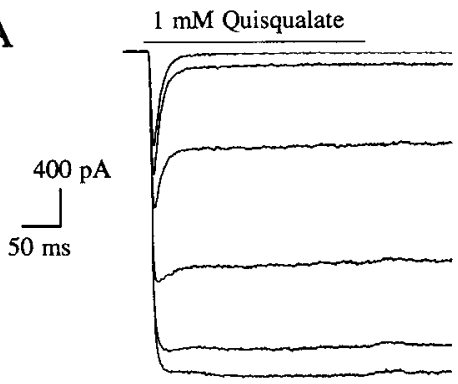

Control

$0.3 \mu \mathrm{M} \mathrm{CYZ}$

$1 \mu \mathrm{M} \mathrm{CYZ}$

$10 \mu \mathrm{M} \mathrm{CYZ}$

$30 \mu \mathrm{M} \mathrm{CYZ}$

$100 \mu \mathrm{M} \mathrm{CYZ}$

C

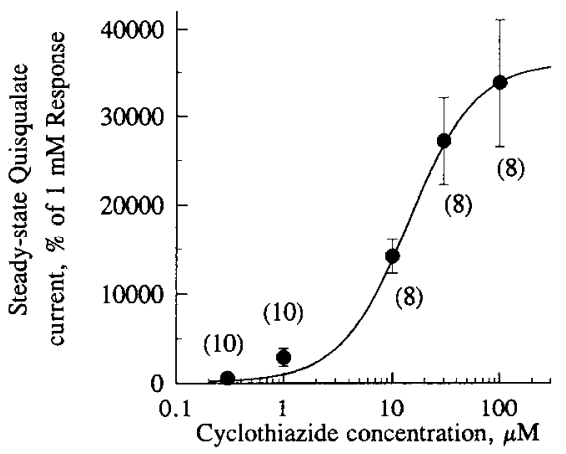

B

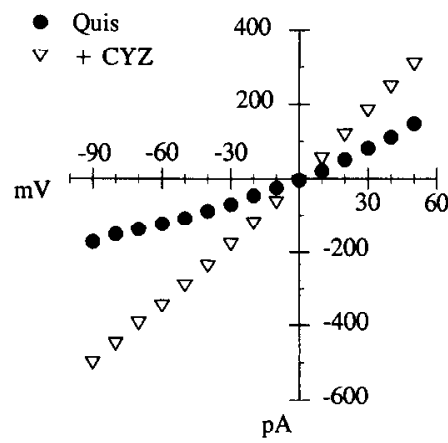

D

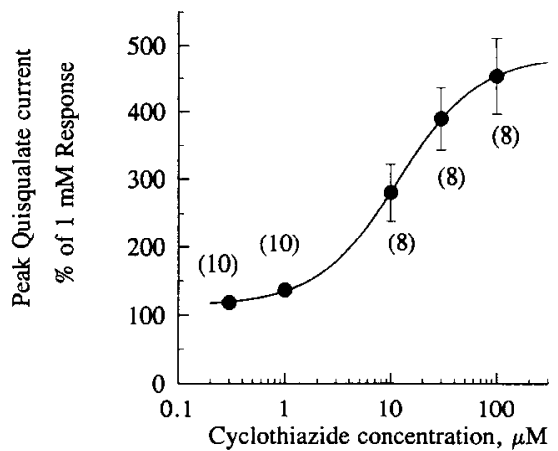

out membrane patches. Rapid solution changes were achieved by alternately applying solutions from the two sides of a theta glass tubing. The flow of the different control and test solutions was independently regulated by solenoid valves, which were in turn regulated by a timing and driving unit linked to the data acquisition computer. The opening of the theta tubing was roughly $200 \mu \mathrm{m}$, and the solutions were gravity fed (2-5 inches). Solution change can be achieved in less than $1 \mathrm{msec}$ (Tang et al., 1989). Glutamate was applied in 200-500-msec-long pulses. Patches containing channel activity in the absence of glutamate were discarded.

For the analysis of burst length distribution, the distribution of all closing events was first determined. The closed time distribution could adequately be fitted by three exponentials. $t_{\text {crit }}$ was defined as three times the intermediate closed time. A burst was defined as groups of channel openings that were separated by closings shorter than $t_{\text {crit }}$. Distributions were fitted by least squares and checked by visual inspection. With distributions that could not be fitted by two exponentials, the longest distribution was determined first.

Spontancous miniature excitatory synaptic currents were recorded by continuous acquisition to computer hard disk using a $5 \mathrm{kHz}$ sampling rate (FETCHEX-pCLAMP or CLAMPEX-pCLAMP software and TL- 1 interface, Axon Instruments, Inc., Foster City, CA), either while on line or from digital audio tapes played back off line. The holding potentials were $-60,-80$, or $-90 \mathrm{mV}$, and are noted in the figure captions. Detection of events, and the measurement of peaks and the times from the peak to half-peak amplitude $\left(t_{1 / 2}\right)$ were accomplished using a computer program written by Jiaxin Que (Washington University, St. Louis, Missouri) in Axobasic programming language (Axon Instruments, Inc.). Measurements of mEPSC frequency were sometimes performed by manually counting events from FETCHEX files using FETCHAN-PCLAMP software.

\section{Results}

Whole-cell current recordings

Rapid step application of L-glutamate or quisqualate evoked a rapid transient current that decayed to a smaller steady-state current. Figure $2 A$ shows the responses of a representative hippocampal neuron to rapid step applications of $1 \mathrm{~mm}$ quisqualate without and with different concentrations of CYZ. CYZ produces dramatic reduction of desensitization as reflected by the magnitude of the steady-state current, as well as an increase in the peak amplitude, without a change in the reversal potential of the steady-state current (Fig. 2B). In the absence of CYZ the steady-state current showed slight outward rectification. One micromolar CYZ increased the slope conductance while the reversal potential remained unchanged close to $0 \mathrm{mV}$, and the outward rectification was reduced (Fig. $2 B$ ). In these experiments, cells used had been in culture $4-5 \mathrm{~d}$, because their relatively small size and limited process outgrowth at this age in vitro optimized rapid and complete application of quisqualate to the cell being recorded. In addition, despite the small size of these cells, the currents activated by $1 \mathrm{~mm}$ quisqualate were often greater than 1 to several nanoamps. Therefore, dSEVC was used to eliminate the contribution of series resistance crror. The rapid application of a high concentration of quisqualate resulted in almost complete desensitization in control conditions. Of the 10 neurons used to generate the concentrationresponse curves in Figure 2, $C$ and $D$, the percentage desensitization $[1-($ steady-state current/peak current) $] \times 100$ was $98.1 \pm 1.06 \%( \pm 1 \mathrm{SD})$, and the desensitization of the peak current was fit by two exponentials, $\tau_{1}=3.27 \pm 1.97 \mathrm{msec}( \pm 1$ $\mathrm{SD})$ and $\tau_{2}=14.7 \pm 6.69 \mathrm{msec}( \pm 1 \mathrm{SD})$. CYZ produced a dramatic increase in steady-state quisqualate current in every cell tested, and there was a concentration-dependent increase in the amplitude of the peak and the steady-state current associated with a change in the kinetics of the quisqualate-evoked currents. There was a 400 -fold enhancement of the steady-state 
A

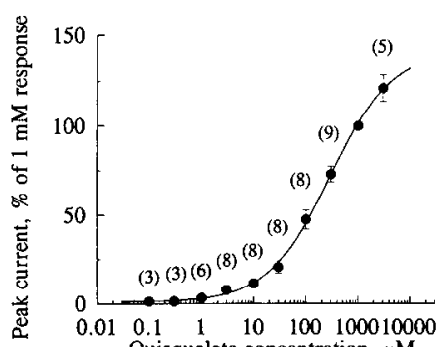

Quisqualate concentration, $\mu \mathrm{M}$
B

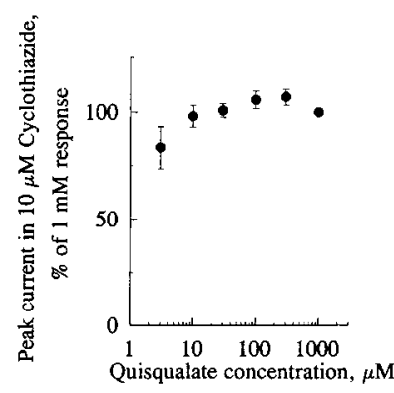

Figure 3. The effect of $\mathrm{CYZ}$ upon the quisqualate concentration-response curve. $A$, Peak currents activated by different concentrations of quisqualate were normalized to the peak current of the response to 1 mm quisqualate; 23 neurons were used to generate this curve, and the numbers in parentheses indicate the number neurons used to generate the data point at that concentration (error bars are SEM). The smooth line was fitted through the data as described in Materials and Methods; the $\mathrm{EC}_{50}$ and maximum response obtained from the curve fit was 280 $\mu \mathrm{M}$ and $140 \%$ of the $1 \mathrm{mM}$ response respectively. The data from $A$ and from Figure $2 D$ indicate that $C Y Z$ increases the maximal response to quisqualate. $B$, Peak currents activated by different concentrations of quisqualate in the presence of $10 \mu \mathrm{M} C Y Z$. The responses were normalized to the $1 \mathrm{mM}$ response. The responses plateau at $10-1000 \mu \mathrm{M}$, with $3 \mu \mathrm{M}$ near the shoulder of the top of the concentration-response curve, indicating a significant left-shift of the quisqualate $\mathrm{EC}_{50}$. Six concentrations of quisqualate were applied to six different neurons to generate these data. The holding potential was $-60 \mathrm{mV}$.

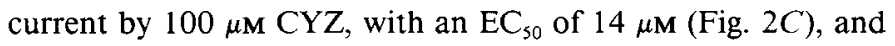

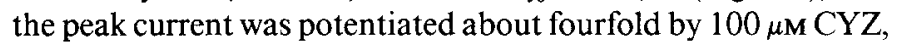
with an $\mathrm{EC}_{50}$ of $12 \mu \mathrm{M}$. The minute steady-state currents recorded in control conditions resulted in tremendous enhancement of the steady-state current in CYZ when normalized to the control response.

One millimolar quisqualate is a saturating concentration (Kiskin et al., 1986; Thio et al., 1991) according to published results from others. We generated a quisqualate concentration-response curve to confirm that $\mathrm{CYZ}$ potentiated the peak response, and to evaluate whether or not $\mathrm{CYZ}$ had an effect upon the $\mathrm{EC}_{50}$ for quisqualate. Twenty-three neurons that were in culture 2-5 $d$ were used to generate the quisqualate concentration-response curve. dSEVC was utilized as described in Materials and Methods in order to eliminate series resistance error. The 23 neurons had a percentage desensitization (see above) of $98.8 \pm 0.89 \%$ to $1 \mathrm{~mm}$ quisqualate. Up to five different concentrations of quisqualate were applied to a single neuron, but often fewer concentrations were tested. All quisqualate responses for a given neuron were normalized to the $1 \mathrm{~mm}$ response for that neuron. The curve fitted through the data (see Materials and Methods) gave an $\mathrm{EC}_{50}$ for the peak quisqualate response of $280 \mu \mathrm{M}$ and a peak response of $140 \%$ of the $1 \mathrm{~mm}$ response (Fig. $3 A$ ). In the presence of $10 \mu \mathrm{M} \mathrm{CYZ}$, the concentration-response relationship of quisqualate was quite different (Fig. $3 B$ ). Quisqualate concentrations between 3 and $1000 \mu \mathrm{M}$ were chosen because the experiments in Figure $3 A$ demonstrated that consistent desensitizing responses could be obtained with as low as $3 \mu \mathrm{M}$ quisqualate, but below that concentration there was usually no peak to steady-state difference. Quisqualate at $3 \mu \mathrm{M}, 10 \mu \mathrm{M}, 30 \mu \mathrm{M}$, $100 \mu \mathrm{M}, 300 \mu \mathrm{M}$, and $1 \mathrm{~mm}$ was applied to six neurons in the

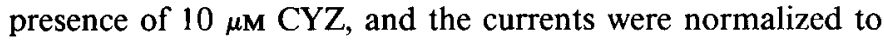

A

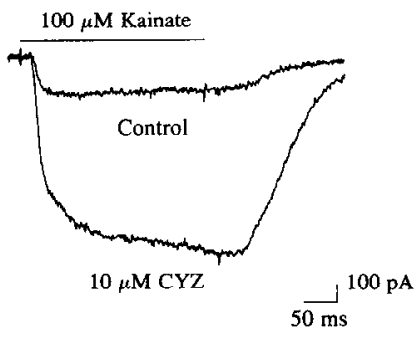

B

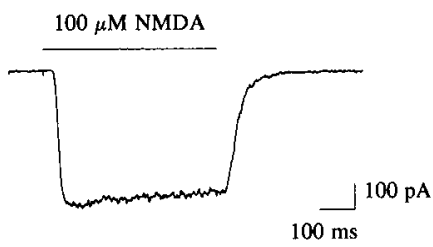

$100 \mu \mathrm{M} \mathrm{NMDA}+10 \mu \mathrm{M} \mathrm{CYZ}$

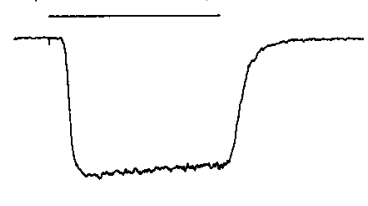

Figure 4. CYZ effects upon kainate-activated $(K A)$ and NMDA-activated currents. $A, \mathrm{CYZ}$ at $10 \mu \mathrm{M}$ increases the amplitude of currents activated by $100 \mu \mathrm{M}$ kainate. The holding potential was $-60 \mathrm{mV}$, and the conditions were the same as in Figures 2 and 3. B, In a different cell, CYZ fails to alter the amplitude and kinetics of currents activated by $100 \mu \mathrm{M}$ NMDA. In experiments represented in $B$ the external buffer contained $10 \mu \mathrm{M}$ glycine, $5 \mu \mathrm{M}$ CNQX and no added magnesium. cSEVC was used, and the holding potential was $-80 \mathrm{mV}$.

the $1 \mathrm{~mm}$ response. The currents were similar in magnitude at all six concentrations, except for being slightly smaller at $3 \mu \mathrm{M}$. In fact, there was sometimes some decrement in the current as the quisqualate concentration was incremented. These data indicate that $3 \mu \mathrm{M}$ is at or near the top shoulder of the peak quisqualate current concentration-response curve in the presence of $10 \mu \mathrm{M} \mathrm{CYZ}$, and indicates that there is a significant leftshift of the quisqualate $\mathrm{EC}_{50}$, perhaps as much as 2 orders of magnitude.

CYZ had apparently two different actions upon kainate currents, although the lack of effects in one situation may be due to technical deficiencies. In five cells that were in culture $5 \mathrm{~d}$, $10 \mu \mathrm{M}$ CYZ produced unequivocal enhancement of the current activated by $100 \mu \mathrm{M}$ kainate (Fig. $4 A$ ), using identical conditions as in Figures 2 and 3. The steady-state current (see Materials and Methods) was $800 \pm 490 \%$ of the control response ( $+1 \mathrm{SD}$, $n=5$ ). However, in previous experiments using cells $10-14 \mathrm{~d}$ in vitro, using $\mathrm{CSEVC}$, and using a less effective perfusion system for eliminating agonist after its application, $10 \mu \mathrm{M} \mathrm{CYZ} \mathrm{had} \mathrm{no}$ effect upon currents activated by $100 \mu \mathrm{M}$ or $600 \mu \mathrm{M}$ kainate (105 $\pm 4.4 \%, n=5 ; 97.1 \pm 3.82 \%, n=5$, respectively; percentages are of control response $\pm 1 \mathrm{SD}$ ). Current rundown was observed in some of these experiments. Under conditions that selectively optimized NMDA mediated currents $\left(10 \mu \mathrm{M}\right.$ glycine, $0 \mathrm{Mg}^{2+}$, $5 \mu \mathrm{M}$ CNQX), $10 \mu \mathrm{M}$ CYZ again did not affect the amplitude $(97 \pm 10 \%$ of control, $n=8)$ or the kinetics of NMDA evoked currents (Fig. $4 B$ ). Application of $10 \mu \mathrm{M} \mathrm{CYZ} \mathrm{alone} \mathrm{to} \mathrm{neurons}$ did not evoke any membrane currents.

The actions of CYZ were discovered in the course of testing different compounds that were chemically related to diazoxide, because of diazoxide's previously observed effects of inhibiting rapid glutamate desensitization (Yamada and Rothman, 1992). A number of other benzothiadiazides (see also Fig. 1, Table 1), HFZ, hydrochlorothiazide (HCTZ), bendroflumethazide (BFZ), TMZ, and diazoxide, also increased the amplitude of the steadystate quisqualate current, but were less potent than CYZ (Fig. 
Table 1.

\begin{tabular}{llll} 
Name of drug & $\begin{array}{c}\text { Abbre- } \\
\text { viation }\end{array}$ & $\mathrm{R}_{\mathbf{3}}$ & $\mathrm{R}_{6}$ \\
\hline Cyclothiazide & $\mathrm{CYZ}$ & See Fig. 1 & See Fig. 1 \\
Hydroflumethiazide & $\mathrm{HFZ}$ & $\mathrm{H}$ & $\mathrm{CF}_{3}$ \\
Hydrochlorothiazide & $\mathrm{HCTZ}$ & $\mathrm{H}$ & $\mathrm{H}$ \\
Trichlormethiazide & $\mathrm{TMZ}$ & $\mathrm{CHCl}_{2}$ & $\mathrm{Cl}$ \\
Bendroflumethiazide & $\mathrm{BFZ}$ & $\mathrm{CH}_{2}$-phenyl & $\mathrm{CF}_{3}$ \\
Diazoxide & $\mathrm{DZ}$ & $\mathrm{See} \mathrm{Fig.} \mathrm{1}$ & $\mathrm{See} \mathrm{Fig.} \mathrm{1}$ \\
Benzthiazide $^{a}$ & $\mathrm{BZ}$ & $\mathrm{CH}_{2} \mathrm{SCH}_{2}$-phenyl & $\mathrm{Cl}$ \\
Chlorothiazide $^{a}$ & $\mathrm{CTZ}$ & $\mathrm{H}$ & $\mathrm{Cl}$ \\
Quinethazone $^{b}$ & $\mathrm{QTZ}$ & $\mathrm{CH}_{2} \mathrm{CH}_{3}$ & $\mathrm{Cl}$ \\
Sulfadiazine & $\mathrm{SDZ}$ & - & - \\
\end{tabular}

3-4 unsaturated; see Figure 1.

"One position is a carbonyl group.

5). At $500 \mu \mathrm{M}$, which was near the limit of solubility for all of these compounds, these latter five compounds enhanced the steady-state current activated by $15 \mu \mathrm{M}$ quisqualate. Two other benzothiadiazides, chlorothiazide and benzthiazide, and two compounds having some chemical similarities to benzothiadiazides, sulfadiazine and quinethazone, had little if any effects on quisqualate-evoked currents (Fig. 5). CYZ, HFZ, HCTZ, TMZ, and BFZ were also tested at $10 \mu \mathrm{M}$ for effects upon quisqualate currents. Two hundred micromolar quisqualate was used because when the steady-state current was smaller the potentiating effects of these drugs was more evident. However, only TMZ produced clear potentiation of the quisqualate current at $10 \mu \mathrm{M}$, and the effect was minimal compared to the effect of 10 $\mu \mathrm{M}$ CYZ (Fig. 5). These earlier experiments had the deficiencies of being performed without MK-801 and bicuculline (as all other experiments described in this report were conducted), with different ages of cells in vitro (7-17 d), and with cSEVC. However, these data are presented to demonstrate that $\mathrm{CYZ}$ eliminated quisqualate desensitization and potentiated the steady-state current at much lower concentrations than the other drugs.

\section{Steady-state single-channel recordings}

Figure $6 \mathrm{~A}$ illustrates one of six outside-out membrane patches used to examine the action of CYZ on steady-state properties of non-NMDA glutamate receptor channels. The main unitary conductances in these six patches was between 15 and $40 \mathrm{pS}$. Analysis of lower-conductance channels was difficult because of the need to increase filtering and because lower-conductance channels tend to have longer open times leading to frequent overlapping events. Channel openings were alternately recorded during exposure to $25 \mu \mathrm{M}$ glutamate (control) and to $10 \mu \mathrm{M}$ glutamate with $10 \mu \mathrm{M} \mathrm{CYZ} \mathrm{(test).} \mathrm{The} \mathrm{lower} \mathrm{glutamate} \mathrm{concen-}$ tration was used with $\mathrm{CYZ}$ in order to minimize overlapping channel openings during exposure to CYZ. Figure $6 B$ illustrates the burst distributions before and during CYZ application. The distribution of all closing events was first determined in the presence of CYZ. The latter distribution could be fitted by three time constants of $0.14,0.97$, and $50.7 \mathrm{msec}$. The $t_{\text {crit }}$ used to define a burst was set at three times the intermediate closed time constant, $2.9 \mathrm{msec}$ in this patch; 867 bursts were recorded during $200 \mathrm{sec}$ exposure to $25 \mu \mathrm{M}$ glutamate; 1539 bursts were recorded during $200 \mathrm{sec}$ exposure to $10 \mu \mathrm{M}$ glutamate and CYZ. Assuming a Hill coefficient of 2, $10 \mu \mathrm{M}$ CYZ induced a 8.9-fold increase in the number of bursts above that expected for the control condition.

The distribution of the burst duration under the control condition could be adequately fitted by two exponentials of 0.18 and $1.7 \mathrm{msec}$. This dual distribution was seen in all six patches with a mean $\pm 1 \mathrm{SD}$ of $0.23 \pm 0.14 \mathrm{msec}$ and $2.3 \pm 1.1 \mathrm{msec}$. After the addition of CYZ the distribution could no longer be fitted by two exponentials. Very long openings that occurred infrequently under control conditions appeared more often in the presence of CYZ. The new distribution required three exponentials of $0.18,2.2$, and $12 \mathrm{msec}$ to fit. The requirement for three exponentials was seen in all six patches $(0.17 \pm 0.06 \mathrm{msec}$, $2.2 \pm 1.1 \mathrm{msec}$, and $12 \pm 4.5 \mathrm{msec}$ ). The briefer openings showed no apparent CYZ-induced change by visual inspection nor by statistical comparison of the fast and intermediate burst durations $(t=0.518, p>0.05$, for the intermediate time constant). The relative weight of the slow component was $29 \%$ in the six patches. The intermediate:fast ratio was $25 \%$ versus $29 \%$ for the control and test condition, respectively. Taking into consideration the addition of the long bursts, there is a calculated 26-fold increase in the total steady-state current. At these low glutamate concentrations the long bursts of openings contributed $70 \%$ of this increase.
Figure 5. The effect of different benzothiadiazide and related drugs upon the steady-state component of quisqualate-activated currents. Different benzothiadiazide analogs are distinguished by their $\mathbf{R}_{3}$ and $\mathbf{R}_{6}$ substituents (see Fig. 1, Table 1). Six benzothiadiazide compounds reduced quisqualate desensitization produced by $15 \mu \mathrm{M}$ quisqualate, with CYZ the most potent. Two similar drugs, benzthiazide $(B Z)$ and chlorothiazide $(C T Z)$, had minimal if any activity. Sulfadiazine $(S D Z)$ and quinethazone $(Q T Z)$ have some chemical similarities to benzothiadiazides; they did not reduce desensitization. Five of the six active compounds were also tested at $10 \mu \mathrm{M}$ against $200 \mu \mathrm{M}$ quisqualate responses; only $\mathrm{CYZ}$ and TMZ had effects at these concentrations. $D Z$, diazoxide.
$15 \mu \mathrm{M}$ Quisqualate

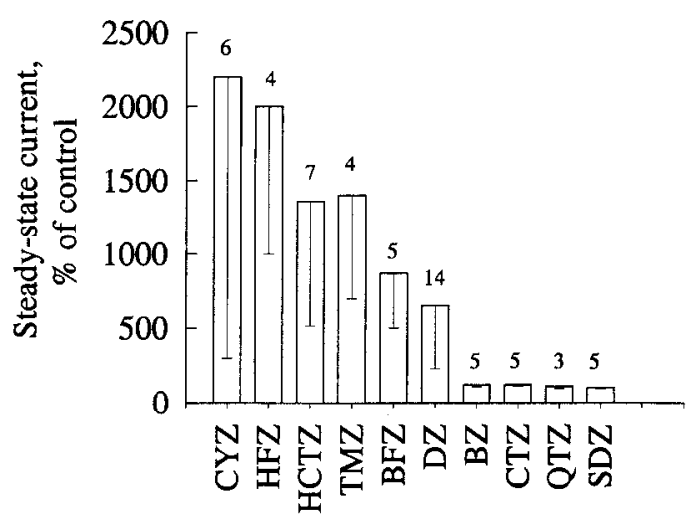

$\begin{array}{ll}\text { Concentrations: } & \text { CYZ } 10 \mu \mathrm{M} \\ & \text { BZ } 250 \mu \mathrm{M} \\ & \text { All others } 500 \mu \mathrm{M}\end{array}$
$200 \mu \mathrm{M}$ Quisqualate

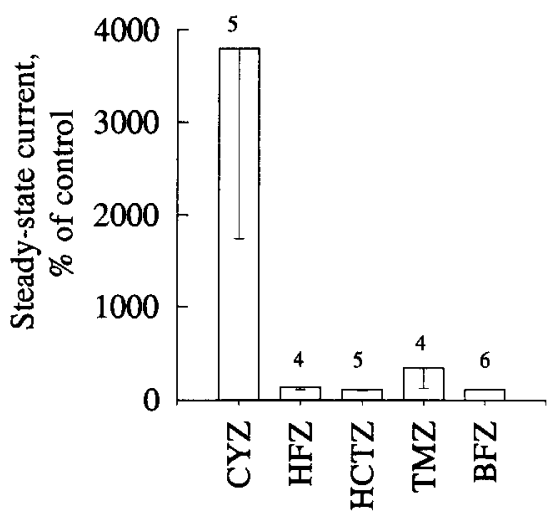

Concentrations: All $10 \mu \mathrm{M}$ 
25 UM Glu
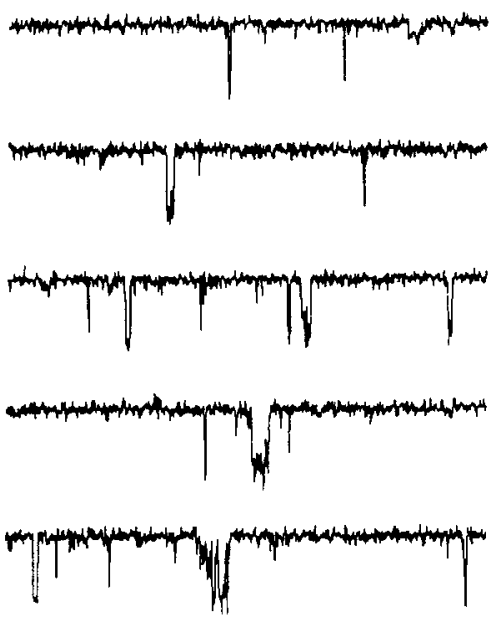

B

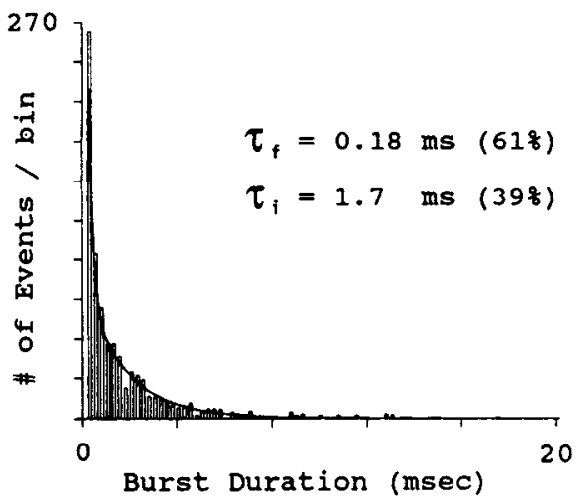

$$
\begin{aligned}
& 10 \underset{\text { UM Glu }}{+ \text { Cyz }} \\
& +{ }^{2}
\end{aligned}
$$
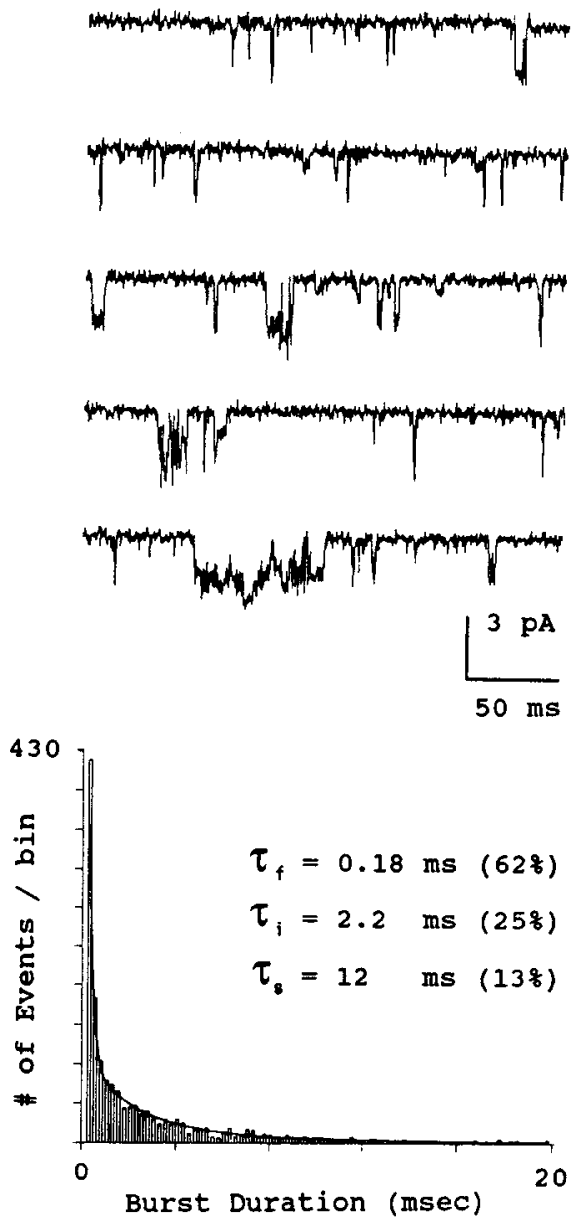

Figure 6. $\mathrm{CYZ}$ increases the number of openings and adds long bursts of openings. $A$, Representative samples of recordings from the same membrane patch are shown with and without CY7. $(10 \mu \mathrm{M})$. Note that the individual openings are unusually brief and that rapid flickering during bursts are often hard to resolve (filtered at $2 \mathrm{kHz}$ ). Holding potential was $-80 \mathrm{mV}$. $B$, The distribution of burst durations are compared. Under control conditions the burst duration can be fitted adequately by the sum of two exponentials. In the presence of CYZ the fit required the sum of three exponentials. The third component reflects the emergence of long bursts that occur only very rarely without $C Y Z$. The fast and intermediate components are not significantly altered even though there has been a significant increase in the total openings. During $200 \mathrm{sec}, 867$ bursts were detected in response to 25 $\mu \mathrm{M}$ glutamate and 1537 bursts were detected in response to $10 \mu \mathrm{M}$ glutamate plus CYZ. Bin width is $0.25 \mathrm{msec}$.

\section{Non-steady-state single-channel recordings}

Rapid kinetic properties of individual non-NMDA glutamate receptor channels can best be studied using high glutamate concentrations. At high concentrations, however, multiple channels are invariably activated in excised patches from hippocampal neurons. One way to obtain patches containing only one or two channels is to use a cell line, NT2-N, that expresses glutamate channels nearly identical to hippocampal glutamate channels but in lower density (Younkin et al., 1993). Figure 7 illustrates an NT2-N patch containing two non-NMDA glutamate channels. Rapid step applications of $1 \mathrm{~mm}$ of glutamate led these channels to open only briefly. The desensitization time constant of the ensemble average of 15 individual traces was $3 \mathrm{msec}$ (top trace).

Addition of CYZ led to a gradual inhibition of rapid desensitization. Multiple repetitive openings gradually incrcascd over $18-20 \mathrm{sec}$. The 15 traces from $25-50 \mathrm{sec}$ were essentially indistinguishable from those at 18-22 sec. The absence of frequent overlapping openings suggests that the long apparent openings were apparently from a single channel. How can a single channel show a graded onset of inhibition? One explanation is that there are two or more CYZ binding sites for each glutamate receptor channel. Multiple binding sites for CYZ make it difficult to discard the possibility that there may be qualitative differences in the kinetic properties between 10 and $100 \mu \mathrm{M} \mathrm{CYZ}$.

The ensemble average of the 30 individual traces is shown on top. A point of particular interest is the rapid deactivation kinetics following rapid removal of glutamate $(2 \mathrm{msec})$. It is clearly faster than the apparent openings induced by CYZ. This finding suggests that the glutamate dissociation rate must be very fast and that CYZ's dominant action at high glutamate concentrations is the greatly increased number of repeat openings and not the prolongation of the open duration.

\section{Non-steady-state macroscopic recordings}

Excised patches containing a large number of channels are useful for studying macroscopic kinetics. Patches from hippocampal neurons typically contain many glutamate channels that desensitize rapidly and profoundly so that the steady-state current can be barely detected. In order to examine whether CYZ has any significant effect on the deactivation kinetics of the steadystate current, two patches with measurable steady-state currents are illustrated in Figure 8. Deactivation under control conditions can be fitted by a single exponential. With the addition of $10 \mu \mathrm{M} \mathrm{CYZ}$, deactivation required two exponentials to fit. The 
Figure 7. The onset of CYZ's action is slow and gradual. The slowness is not diffusion limited and the gradual onset is not a population averaging effect. There was a maximum of two nonNMDA glutamate channels in this membrane patch obtained from the NT2 human cell line induced to express glutamate channels at low density. In response to 45 step applications of 1 mM glutamate there were no null responses and there were no responses higher than two simultaneous openings at any time. $A$, One or both channels open rapidly, briefly and apparently only once (with filtering at $2 \mathrm{kHz}$ ) to 250 msec-long applications of glutamate. The desensitization of the ensemble averaged current (shown at the top) can be well fitted by a single exponential of $3.1 \mathrm{msec}$. $B$, After addition of $10 \mu \mathrm{M}$ CYZ, glutamate was again applied at $1.5 \mathrm{sec}$ intervals. The times of the responses are marked on the left. The responses within the first $3 \mathrm{sec}$ showed possible prolongation of the burst length followed eventually by single very long apparent bursts of the same duration as the glutamate pulse. Note that the deactivation rate of the ensemble averaged currents $(2.2 \mathrm{msec})$ is significantly faster than would be predicted by the apparent long bursts. The holding potential was $-80 \mathrm{mV}$. The amplitude scale of the average traces is double that for the individual traces.

$A$

$1 \mathrm{mM} \mathrm{Glu}$
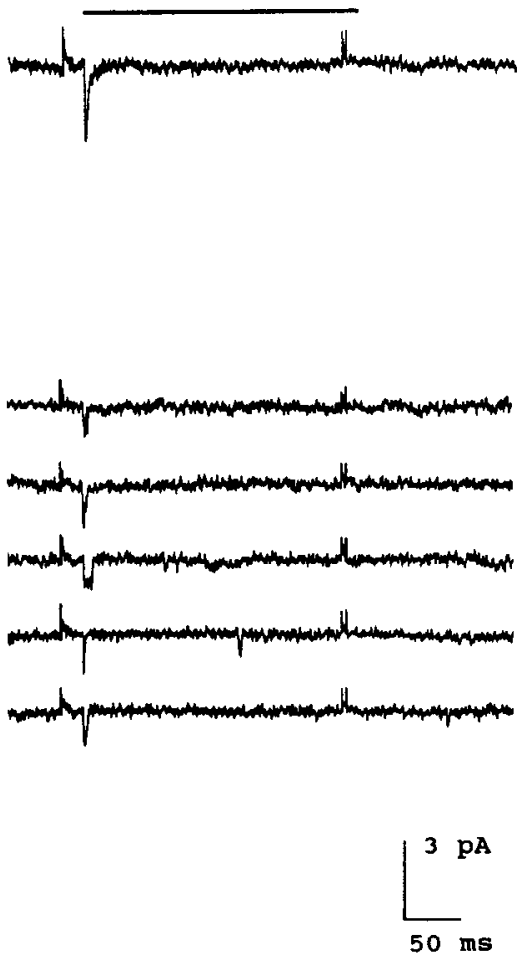

$\mathrm{B}$
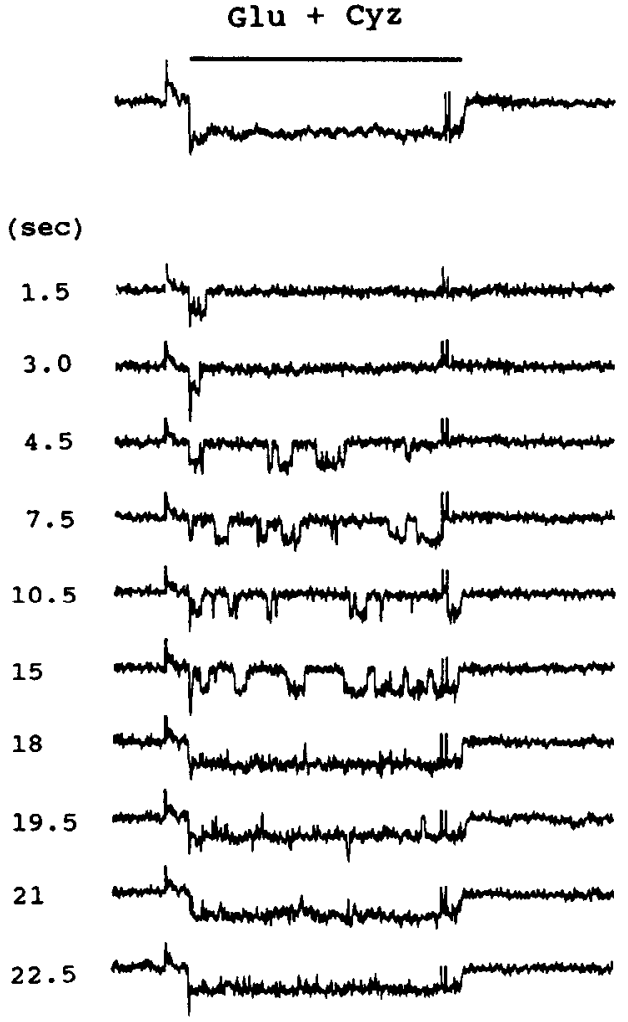

speed of the fast component remained unchanged from control in five out of five patches. The observation that when kainate was used as the agonist the deactivation rate was often less than $1 \mathrm{msec}$ suggests that these measurements of deactivation were not limited by the speed of the concentration jumps but reflected the differing gating and dissociation kinetics of the receptor channels. The new slower component of deactivation can be seen as arising from long bursts of openings extending well past the removal of the glutamate. As expected, the unitary conductances of these bursts were unchanged from control. At these higher glutamate concentrations $(200 \mu \mathrm{M}$ in Fig. $8 A, 100 \mu \mathrm{M}$ in Fig. $8 B$ ) the long bursts contributed less to the increase in the steady-state current $(18 \%$ in $A, 37 \%$ in $B)$. At near-maximal glutamate concentration ( $1 \mathrm{~mm}$ ) CYZ increased the peak current by only $6 \%(n=10)$ in excised patches.

\section{Recordings of spontaneous $\mathrm{mEPSCs}$}

Because diazoxide was shown to be a gating modifier of the AMPA channel and also to be a modulator of the evoked fast EPSCs (Yamada and Rothman, 1992), the actions on the fast EPSC by the more potent benzothiadiazide CYZ were examined closely in this study. Initial attempts to study electrically evoked EPSCs were hindered by polysynaptic activity produced by CYZ. Spontaneous mEPSCs enabled examination of the effects of CYZ upon synaptic responses unhindered by polysynaptic activity, asynchronous transmitter release, and other presynaptic factors. Figure 9 illustrates mEPSCs recorded in the presence of bicuculline and MK-801. Complete elimination by $5 \mu \mathrm{M}$ CNQX confirms that they were mediated by non-NMDA channels. In the presence of $10 \mu \mathrm{M} \mathrm{CYZ} \mathrm{the} \mathrm{mean} \mathrm{peak} \mathrm{amplitude} \mathrm{of} \mathrm{the}$
mEPSC increased from $-8.0 \pm 4.5 \mathrm{pA}$ to $-15 \pm 6.7 \mathrm{pA}$, and the time from the peak to half-peak amplitude $\left(t_{1 / 2}\right)$ increased from $2.6 \pm 1.7 \mathrm{msec}$ to $5.8 \pm 2.8 \mathrm{msec}$. We used 472 events in control conditions and 1648 events in $10 \mu \mathrm{M} \mathrm{CYZ}$ for analysis. In seven neurons from which mEPSCs were recorded, the control frequency of mEPSCs was $1.64 \pm 1.28 / \mathrm{sec}$ (duration of recording, 142-284 sec) with a range of $0.25-3.1 / \mathrm{sec}$. CYZ at concentrations of $2 \mu \mathrm{M}$ (one cell), $10 \mu \mathrm{M}$ (three cells), and 100 $\mu \mathrm{M}$ (three cells) produced an increase in mEPSC frequency to $320 \pm 208 \%$ of control (range, 155-628\%) with no definite concentration dependence. After washing out the CYZ the frequency returned to $144 \pm 84.6 \%$ of the control frequency.

CYZ induced the appearance of two components to the fast mEPSC decay when the recorded signal has fast rise times and low background noise. In the presence of $\mathrm{CYZ}$ the gating of individual channels mediating the fast mEPSC can frequently be visualized. Figure $10 \mathrm{~A}$ illustrates a number mEPSCs recorded from a small non-pyramidal-shaped hippocampal neuron with $10-90 \%$ rise times less than $1 \mathrm{msec}$. During a $60 \mathrm{sec}$ exposure to $10 \mu \mathrm{M}$ CYZ 54 mEPSCs were recorded. During $30 \mathrm{sec}$ prior to $\mathrm{CYZ}$ exposure and $30 \mathrm{sec}$ following washout $58 \mathrm{mEPSCs}$ were recorded. There was at least a 1 min interval between recordings following each change in solution. Figure $10 B$ shows the ensemble average of these mEPSCs. There was only a small increase in the peak amplitude in this cell. In Figure $10 C$ the averaged traces were normalized and superimposed to better compare the kinetics of their decay. CYZ at $10 \mu \mathrm{M}$ clearly added a small second slow component $(20 \mathrm{msec}, 10 \%)$. Of interest is the observation that $\mathrm{CYZ}$ at the same submaximal concentration that did not prolong the fast deactivation rate prolonged 
A
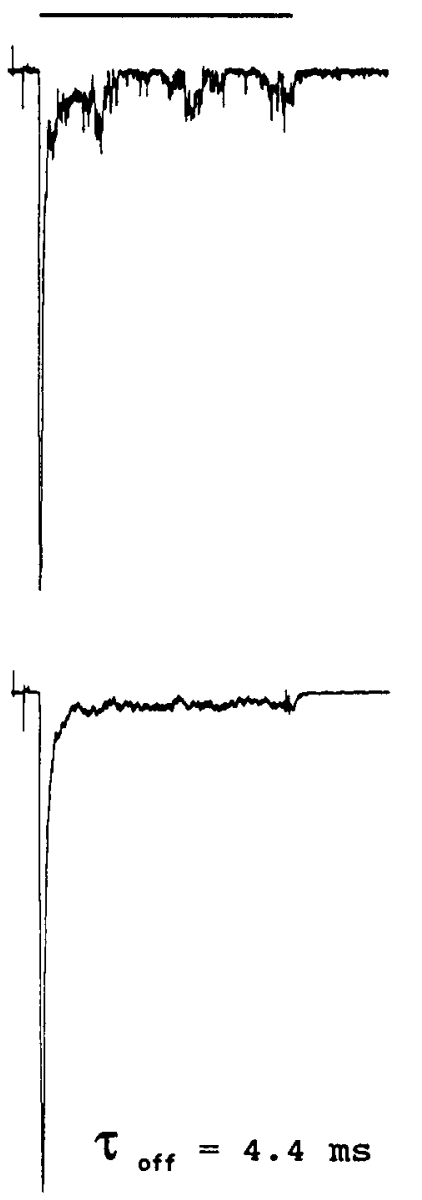

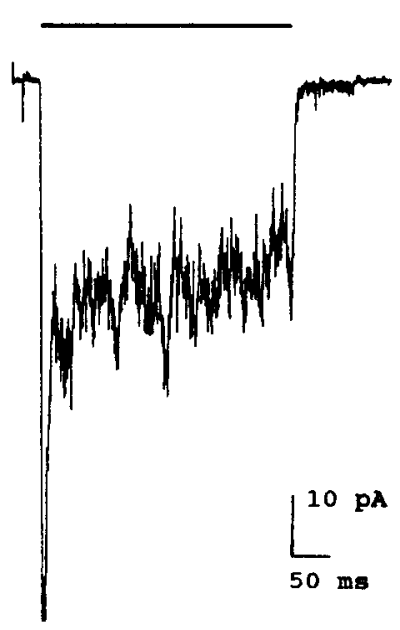

$$
+\mathrm{Cyz}
$$

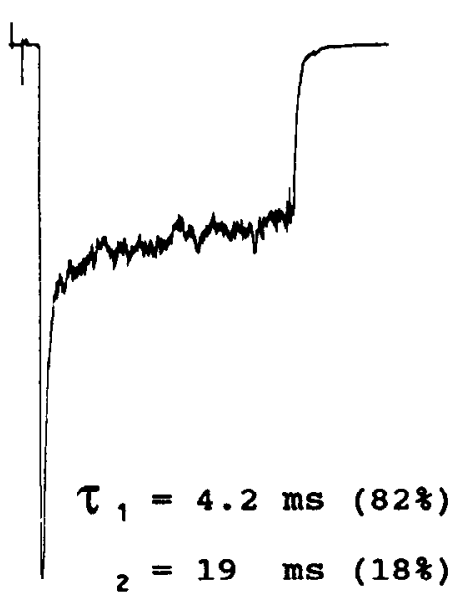

B
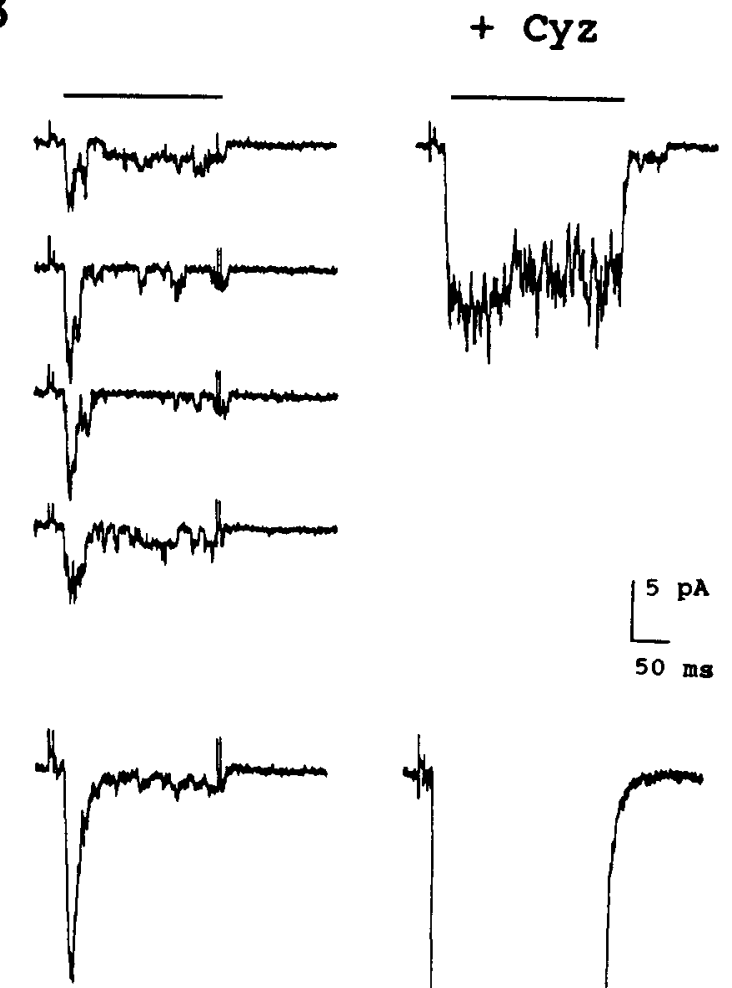

$\tau_{\text {off }}=2.3 \mathrm{~ms}$

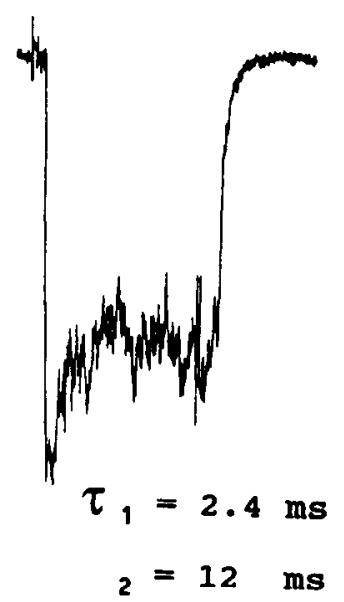

$(638)$

Figure 8. Macroscopic current recordings show that $10 \mu \mathrm{M} \mathrm{CYZ} \mathrm{has} \mathrm{minimal} \mathrm{effects} \mathrm{on} \mathrm{the} \mathrm{deactivation} \mathrm{kinetics} \mathrm{despite} \mathrm{very} \mathrm{prominent} \mathrm{en-}$ hancement of the steady-state current. $A$ and $B$ show responses of membrane patches from two different hippocampal neurons to applications of $200 \mu \mathrm{M}(A)$ and $100 \mu \mathrm{M}(B)$ glutamate. The top traces show individual recordings and the bottom traces show the ensemble averaged signal of 10 individual recordings. The deactivation rates were fitted from the averaged signals.

the fast component of the EPSC decay. Also of interest is the similarity between the amplitudes of the discrete decreases in the mEPSC and the unitary conductances of non-NMDA glutamate channels excised from the neuron cell body.

\section{Discussion}

\section{CYZ effects upon whole-cell currents}

The application of $1 \mathrm{~mm}$ quisqualate to voltage-clamped hippocampal neurons in whole-cell configuration activates large peak currents that almost completely desensitize to minute steady-state currents. These peak and steady-state currents were enhanced up to 4 - and 400-fold, respectively, by CYZ, whose action had $\mathrm{EC}_{50}$ values of 12 and $14 \mu \mathrm{M}$ for the peak and steadystate current, respectively. One very useful aspect of CYZ's effect is its reversibility. However, the time of onset and washout of CYZ's actions is not rapid and is unlikely to be diffusion limited. A requirement for multiple binding may account for some of the delay in onset of the full effect (Fig. 7), but does not adequately explain the 15-20 sec required for CYZ's effects to equilibrate. Another explanation is that $\mathrm{CYZ}$ must reach a seques- tered extracellular or intramembranous site on the receptorchannel complex. The absence of a CYZ effect when CYZ is added to the intracellular solution (K. A. Yamada, unpublished observation) suggests that $\mathrm{CYZ}$ does not act at an intracellular location, and also reduces the likelihood that it has an intramembranous site of action.

The left-shift of the quisqualate peak current concentrationresponse relation by CYZ could have multiple explanations. The shift may reflect a change in the receptor's affinity for quisqualate after binding CYZ. Patneau et al. (1992a) and Vyklicky et al. (1991) have suggested that the macroscopic current observed from different "desensitizing and nondesensitizing" agonists reflects their relative affinities for desensitized and activatable states of the glutamate receptor. Support for this notion is the recent observation of rapidly desensitizing kainate responses in avian central neurons (Raman and Trussell, 1992), and the observation that kainate currents are potentiated by CYZ. It is still possible that CYZ inhibits desensitization without affecting the affinity for quisqualate, because the peak current concentration-response relation may be affected by the concen- 


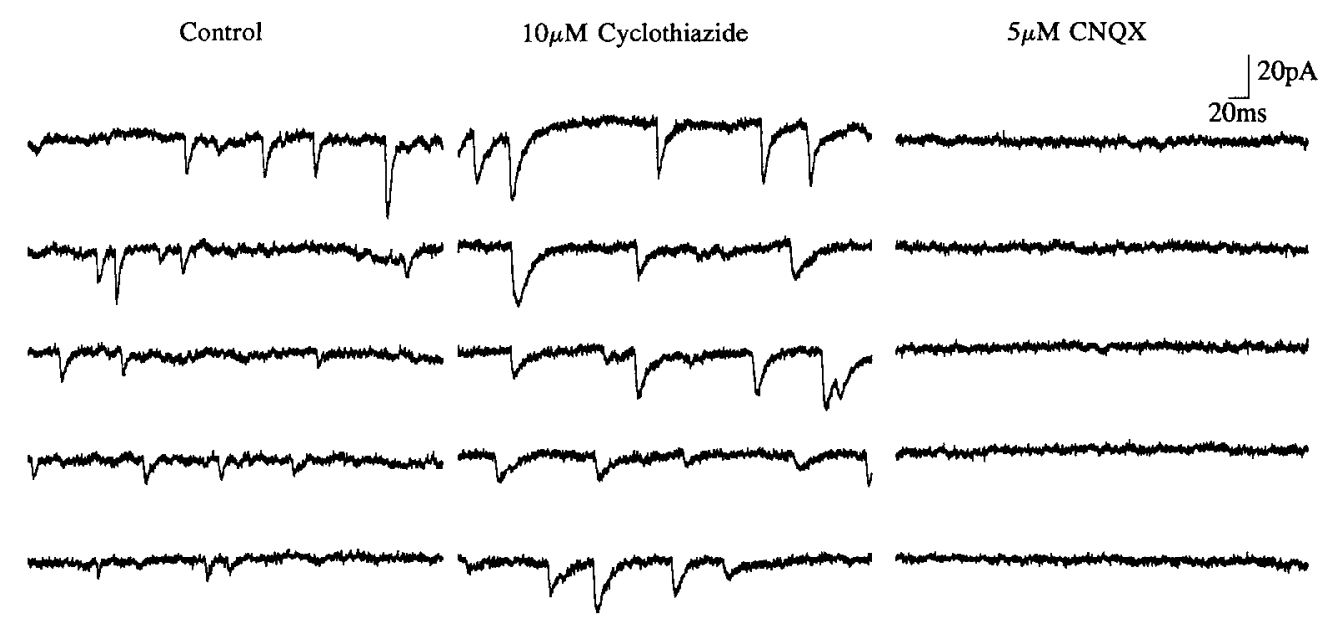

Figure 9. The effect of CYZ upon spontaneous mEPSCs. Shown here are selected examples of mEPSCs from the same neuron in different conditions. The holding potential was $-60 \mathrm{mV}$. The extracellular solution contained $20 \mu \mathrm{M}$ bicuculline and $20 \mu \mathrm{M}$ MK-801 to block GABA and NMDA conductances. Left, mEPSCs in control buffcr. Center, CYZ at $10 \mu \mathrm{M}$ increases the pcak amplitude and prolongs the decay of these synaptic events. Note in the top tracing of this panel that the three events to the right appear to have an initial decay followed by a second more slowly decaying component. Right, CNQX at $5 \mu \mathrm{M}$ eliminated all spontaneous synaptic activity, confirming that the mEPSCs were mediated by nonNMDA receptors. These data were selected from continuous recordings that contained many spontaneous events. Continuous records of spontaneous events were analyzed for the peak and the time from the peak to half-peak amplitude $\left(t_{1 / 2}\right)$ as described in Materials and Methods. The means \pm $1 \mathrm{SD}$ for these values were $-8.0 \pm 4.5 \mathrm{pA}$, and $2.6 \pm 1.7 \mathrm{msec}$ in control buffer, respectively $(n=427)$. In $10 \mu \mathrm{M} \mathrm{CYZ}$ they were $-15 \pm 6.7 \mathrm{pA}$, and $5.8 \pm 2.8 \mathrm{msec}$, respectively $(n=1648)$.

tration dependence of desensitization (Thio et al., 1991), and it may not be accurate to model the peak response as an equilibrium condition.

\section{Structure-activity relationships}

The benzothiadiazides, more commonly called "thiazides," were devcloped and synthesized as diuretics. A number of these (i.e., HCTZ) are among the most commonly prescribed medications in clinical use. There appears to be little relationship between the diuretic actions of these compounds and their ability to reduce glutamate receptor desensitization. Compounds active against desensitization have a closed sulfonamide ring attached to a halogenated benzene ring. The position and type of halogenated substituent do not seem to be critical, but the presence of a halogenated substituent may be important for activity (Bertolino et al., 1992). As demonstrated by the activity of diazoxide, the sulfonamide substituent on the aromatic ring, which is absolutely required for diuretic activity (Beyer and Baer, 1961; Maren and Wiley, 1964), is not required for the effect on glutamate desensitization. Quinethazone, a non-thiazide that does not reduce glutamate desensitization, is chemically similar to TMZ, except that the $\mathrm{R}_{3}$ substituent is $-\mathrm{CH}_{2} \mathrm{CH}_{3}$ instead of $-\mathrm{CIICl}_{2}$ and the hetcrocyclic ring is a carbamide instead of a sulfonamide. Quinethazone's lack of activity suggests that a sulfonamide linkage in the $-\mathrm{SO}_{2}-\mathrm{N}-\mathrm{CR}-\mathrm{N}-$ part of the heterocyclic ring is required for activity. Moreover, the fact that sulfadiazine has an unrestricted $-\mathrm{SO}_{2}-\mathrm{N}-\mathrm{CR}-\mathrm{N}-$ sulfonamide linkage suggests that activity requires the sulfonamide linkage to be constrained as a heterocyclic ring. Few inferences can be made about the structure-activity requirements for the $\mathrm{R}_{3}$ or $R_{6}$ substituents. The $R_{3}$ position may be unsubstituted and still effectively reduce desensitization (e.g., HCTZ and HFZ). It is interesting, but without an obvious structure-activity explanation, that HCTZ and chlorothiazide differing only by saturation at the $3-4$ position of the heterocyclic ring have strikingly different activity. Similarly, benzthiazide and BFZ differ slightly at the $\mathrm{R}_{3}$ substituent and also have striking differences in their activities. In this latter example one may speculate that the site of action for benzothiadiazides on the non-NMDA glutamate receptor channel is sensitive to a maximum size of the $R_{3}$ substituent in which differences of only a few angstroms preclude activity against rapid desensitization.

\section{Comparisons between macroscopic and microscopic recordings}

A notable difference between whole-cell and excised patch recording is the relatively modest increase in the peak current induced by CYZ in excised outside-out membrane patches. A possible explanation is that a significant degree of desensitization may still occur with concentration jumps under whole-cell recordings without $\mathrm{CYZ}$. Alternatively, it is possible that structural or intracellular factors regulating whole-cell desensitization are eliminated by removal of the membrane patch from the neuron.

A second apparent difference is the variable degree of enhancement for the steady-state currents. These differences may be explained on the basis of different degree of desensitization in the control conditions. For example, when using $1 \mathrm{~mm}$ quisqualate versus 10-25 $\mu \mathrm{M}$ glutamate, one expects different degrees of steady-state desensitization. This may explain the observation that in response to $10 \mu \mathrm{M} \mathrm{CYZ}$ there is between 100 - and 150-fold enhancement in the former case and only a 26-fold enhancement in the latter case.

A third apparent difference is the varying degree of contribution of the long bursts to the total steady-state current. This difference may be explained by the differing glutamate concentrations employed in each situation. At 10-25 $\mu \mathrm{m}$ glutamate the relative contribution of the longer bursts is substantial (calculated to be $70 \%$; Fig. 6 ). At $100-200 \mu \mathrm{M}$ the relative contribution becomes $37-18 \%$ (calculated from deactivation kinetics; Fig. 8). One explanation may be that given a fixed ratio of channels that bursts versus those that open briefly, it is the channels with the lower open probability $\left(P_{o}\right)$ at low glutamate concentrations that 
will have the greater opportunity to increase their relative contribution. If the latter explanation is valid this may be another indirect approach to estimating concentration of synaptically released glutamate (Clements et al., 1992). In the example shown in Figure 10 the relatively small contribution of the slow component to the peak mEPSC would suggest a high concentration of synaptically released glutamate. Validation of this conclusion will require a more thorough documentation of deactivation and EPSC kinetics at varying glutamate concentrations.

\section{Comparisons between microscopic and synaptic recordings}

Comparisons of the actions of CYZ between microscopic and synaptic recordings provide a number of interesting insights into mechanisms underlying fast excitatory transmission. Good correlation exists between the kinetics of the long bursts as determined from steady-state burst length deactivation kinetics, and the kinetics of the slow tail of the mEPSC induced by CYZ. Furthermore, the steplike decay of the fast $\mathrm{mEPSC}$ in CYZ have conductances similar to the single-channel conductances of somal non-NMDA glutamate channels. It further shows that in nonpyramidal neurons high-conductance channels contribute significantly to the fast EPSC (Tang et al., 1989; Wyllie et al., 1993). These recordings suggest that only a small number of non-NMDA channels need to reside at a single synaptic site.

A discrepancy between the kinetics of the fast component of the mEPSC and the kinetics of the non-NMDA glutamate receptor deactivation remains to be fully explained. The experience with the nicotinic $\mathrm{ACh}$ receptor channels at the muscle end-plate and NMDA channels predicts that deactivation kinetics should fully explain the kinetics of the EPSC's mediated by these channels (Magleby and Stevens, 1972; Lester et al., 1990). Fast concentration jumps cannot measure the deactivation kinetics expected from the briefest openings $(0.18 \mathrm{msec}$; Fig. 6), but they should accurately measure the deactivation kinetics expected from the intermediate length openings (1.1$3.8 \mathrm{msec}, n=6$ ). At the submaximal CYZ concentration of 10 $\mu_{\mathrm{M}}$ there was neither a change in the intermediate burst length nor a change in the fast deactivation kinetics. At this CYZ concentration there was a consistent increase in the faster component of the MEPSC, as well as the enhancement of a second slower component. Similar effects upon the EPSC by CYZ have been reported by Patneau et al. (1992b). One explanation is that synaptic non-NMDA glutamate channels may significantly desensitize during each vesicular release of glutamate. The data here suggest that the contribution of rapid desensitization to the decay of the fast EPSC is measurable. CYZ offers more direct means to address the role of rapid desensitization. These include examination of the effect of CYZ on the amplitude of the second of closely paircd mEPSCs gencrated at the samc synaptic sitc. These more direct examinations could enable one to establish more clearly whether or not rapid desensitization influences the decay of the glutamatergic EPSC.

\section{A hypothesis on CYZ's mechanism of action}

Under normal circumstances the binding of glutamate leads to a conformational change where the desensitized state is energetically far more stable than either the closed or open states. It is proposed that the binding of two or more CYZ molecules destabilizes the desensitized state. One way to explain the appearance of long bursts without adding more open states is to postulate that the desensitized state can be entered from either the open or the closed state and that return to the open state

$A$

Control<smiles>CC(C)N</smiles>

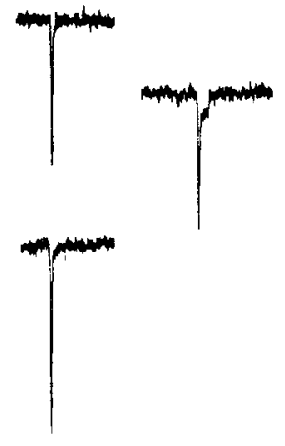

B

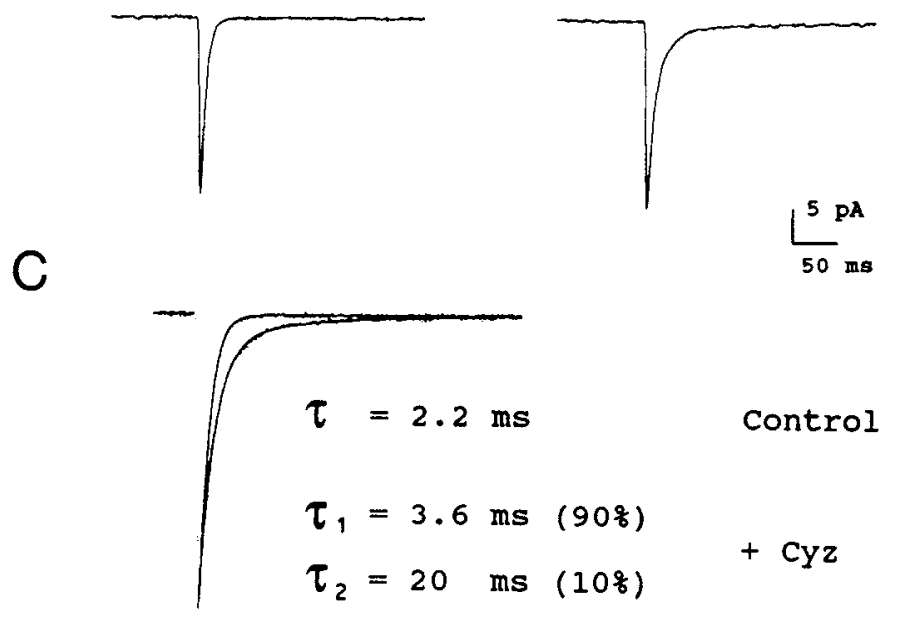

Figure 10. Recordings of mEPSCs from a neuron with rapid rise times show the emergence of a slow synaptic current component and prolongation of the fast current component with the addition of $10 \mu \mathrm{M} \mathrm{CYZ}$. $A$, In recordings with low-background-noise mEPSCs often show steplike decays after the addition of CYZ. $B$, Fifty-eight mEPSCs were detected and averaged during CYZ. $C$, The normalized averaged synaptic currents were superimposed to better illustrate changes in their kinetics. Under control conditions the decay can be well fitted by a single exponential of $2.2 \mathrm{msec}$. During CYZ application the decay required the sum of two exponentials to fit. There was an increase in the faster component as well the addition of a much slower component.

from the desensitized state becomes measurable in the presence of CYZ. It is also proposed that the destabilization of the desensitized state is translated predominantly as increases in the two return steps from desensitization rather than decreases in the entry into desensitization. This distinction is made in order to account more easily for the relatively small increase in the maximal peak current in excised patch recordings and the insignificant changes in the briefer open durations. 


\section{Physiological roles of desensitization}

The data presented earlier suggest that rapid desensitization probably makes a measurable contribution to the decay of the mEPSC. However, the EPSC time course is relatively unaffected despite complete elimination of desensitization. Therefore, desensitization is not likely to serve a dominant role in terminating the EPSC, in the same way that rapid sodium channel inactivation serves to terminate the action potential. Moreover, tremendous variation exists among desensitization rates (1.5-18 msec) between different hippocampal neurons (Tang and Shi, 1991; Livsey and Vicini, 1993). In contrast, deactivation rates are more rapid and vary least $(2-3 \mathrm{msec})$ between different hippocampal neurons (Colquhoun et al., 1992; Livsey and Vicini, 1993). These observations suggest that deactivation kinetics, rather than desensitization, are the predominant and more consistent determinants of the fast EPSC time course.

Rapid desensitization may be important in other physiological processes. For example, desensitization may enable neurons to begin processing closely timed glutamatergic signals at the level of individual synapses. If the glutamate receptor channels at a synaptic site desensitize rapidly (rapid and slow are relative to the frequency of incoming signals), only the first of a rapid sequence of synaptically released vesicles will maximally opcn the channels at this synapse. The synapse responds as a differentiator. In contrast, if the receptors desensitize slowly the synapse will integrate the sequence of incoming signals. The wide variation in desensitization rates in different neurons and synapses may bias them to serve either as integrators or differentiators at the level of individual synapses.

Another possible role for rapid desensitization is that it protects neurons against non-NMDA-mediated excitotoxicity. If such was the case, then reduction of desensitization would be expected to lead to increased excitotoxic injury. Supporting this idea are in vitro studies, in which non-NMDA-mediated excitotoxic neuronal injury was observed with addition of CYZ in conditions that otherwise would not have caused this type of pathology (Moudy et al., 1992; Bateman et al., 1993; Zorumski et al., 1993). Enhancing desensitization (see below) may be a new target for developing neuroprotective agents.

Is rapid desensitization endogenously regulated? The extent of desensitization varies widely between different neurons and excised patches. Furthermore, long bursts of openings that can be terminated by rapid removal of glutamate similar to that induced by CYZ can occasionally be seen in its absence (C. M. Tang, unpublished observation), suggesting that CYZ may enhance channel activity that is less commonly seen, but is within the normal repertoire of non-NMDA glutamate channels. Although no endogenous benzothiadiazide-like compounds have yet to be identified, the finding of a family of compounds that reversibly and in a concentration-dependent manner reduce rapid desensitization suggests that such compounds could interact at a specific site to modulate glutamate desensitization. The recent observation that an atypical benzodiazepine, GYKI 52466, transforms a nondesensitizing kainate response to one that resembles a desensitizing response and counteracts the effects of $\mathrm{CYZ}$ in a concentration-dependent fashion (Zorumski et al., 1993) suggests that GYKI 52466 may oppose CYZ's effects by acting at such a postulated modulatory site. Palmer and Lodge (1993) have observed that CYZ reverses the inhibition of AMPA responses by GYKI 53655, but not NBQX (2,3-dihydroxy-6nitro-7-sulfamoyl-benzo(F)-quinoxaline, a quinoxalinedione- competitive AMPA antagonist). These observations are consistent with the hypothesis that CYZ and certain 2,3-benzodiazepines interact a specific regulatory site on the glutamate receptor channel complex.

The discovery of CYZ and some of its related benzothiadiazides as gating modifiers for non-NMDA channels promises to facilitate the study of a variety of fundamentally important questions.

\section{References}

Ascher P, Bregestovski P, Nowak L (1988) N-methyl-D-aspartateactivated channels of mouse central neurones in magnesium-free solutions. J Physiol (Lond) 399:207-226.

Bateman MC, Yamada KA, Goldberg MP (1993) AMPA receptor desensitization in hypoxic neuronal injury in vitro. Neurology 43[Supp] 2]:A339.

Bertolino M, DiBella M, Baraldi M, Vicini S, Costa E (1992) Positive allosteric modulation of non-NMDA receptors in hippocampal rat brain slices. Soc Neurosci Abstr 18:1458.

Beyer KH, Baer JE (1961) Physiological basis for the action of newer diuretic agents. Pharmacol Rev 13:517-562.

Clements JD, Lester RAJ, Tong G, Jahr CE, Westbrook GL (1992) The time course of glutamate in the synaptic cleft. Science 258:14981501 .

Colquhoun D, Jonas P, Sakmann B (1992) Action of brief pulses of glutamate on AMPA/KA receptors in patches from different neurones of rat hippocampal slices. J Physiol (Lond) 458:261-287.

Forsythe ID, Westbrook GL (1988) Slow excitatory postsynaptic currents mediated by $N$-methyl-D-aspartate receptors on cultured mouse central neurones. J Physiol (I ond) 396:515-533.

Hamill OP, Marty A, Neher E, Sakmann B, Sigworth FJ (1981) Improved patch-clamp techniques for high-resolution current recording from cells and cell-free membrane patches. Pfluegers Arch 391:85100.

Hestrin S, Nicoll RA, Perkel DJ, Sah P (1990) Analysis of excitatory synaptic action in pyramidal cells using whole-cell recording from rat hippocampal slices. J Physiol (Lond) 422:203-225.

Isaacson JS, Nicoll RA (1991) Aniracetam reduces glutamate receptor desensitization and slows the decay of fast excitatory synaptic currents in the hippocampus. Proc Natl Acad Sci USA 88:10936-10940.

Kiskin NI, Krishtal OA, Tsyndrenko AY (1986) Excitatory amino acid receptors in hippocampal neurons: kainate fails to desensitize them. Neurosci Lett 63:225-230.

Lester AJ, Clements JD, Westbrook GL, Jahr CE (1990) Channel kinetics determine the time course of NMDA receptor-mediated synaptic currents. Nature 346:565-567.

Lin SS, Levitan IB (1991) Concanavilin $\Lambda$ : a tool to investigate neuronal plasticity. Trends Neurosci 14:273-277.

Livsey CT, Vicini S (1993) Glutamate-activated currents with slower desensitization rates in outside-out patches from spiny vs. aspiny hippocampal hilar neurons. Soc Neurosci Abstr 18:804.

Magleby KL, Stevens CF (1972) A quantitative description of endplate currents. J Physiol (Lond) 223:173-197.

Maren TH, Wiley CE (1964) Renal activity and pharmacology of $N$-acyl and related sulfonamides. J Pharmacol Exp Ther 143:230242.

Mayer ML, Westbrook GL (1987) The physiology of excitatory amino acids in the vertebrate central nervous system. Prog Neurobiol 28: 197-276.

Mayer ML, Vyklicky L Jr, Clements JD (1989) Regulation of NMDA receptor desensitization in mousc hippocampal ncurons by glycine. Nature 338:425-427.

Moudy AM, Yamada KA, Rothman SM (1992) Desensitization changes the pharmacology of glutamate neurotoxicity. Soc Neurosci Abstr 18: 757.

Palmer AJ, Lodge D (1993) Cyclothiazide reverses AMPA receptor antagonism of the 2,3-benzodiazepine, GYKI 53655. Eur J Pharmacol 244:193-194.

Patneau DK, Mayer ML, Jane DE, Watkins JC (1992a) Activation and desensitization of AMPA/kainate receptors by novel derivatives of willardiine. J Neurosci 12:595-606.

Patneau DK, Vyklicky L Jr, Mayer ML (1992b) Cyclothiazide modulates excitatory synaptic transmission and AMPA/kainate receptor desensitization in hippocampal cultures. Soc Neurosci Abstr 18:248. 
Raman IM, Trussell LO (1992) The kinetics of the response to glutamate and kainate in neurons of the avian cochlear nucleus. Neuron 9:173-186

Tang C-M, Shi Q-Y (1991) The diversity of non-NMDA channels reflects the diversity of differing subsets of hippocampal neurons. Soc Neurosci Abstr 17:1331.

Tang C-M, Dichter M, Morad M (1989) Quisqualate activates a rapidly inactivating high conductance ionic channel in hippocampal neurons. Science 243:1474-1477.

Tang C-M, Shi Q-Y, Katchman A, Lynch G (1991) Modulation of the time course of fast EPSCs and glutamate channel kinetics by aniracetam. Science 254:288-290.

Thesleff S (1955) The mode of neuromuscular blockade caused by acetylcholine, nicotine, decamethonium and succinylcholine. Acta Physiol Scand 34:218-231.

Thio LL, Clifford DB, Zorumski CF (1991) Characterization of quisqualate receptor desensitization in cultured postnatal rat hippocampal neurons. J Neurosci 11:3430-3441.

Thio LL, Clark GD, Clifford DB, Zorumski CF (1992a) Wheat germ agglutinin enhances EPSCs in cultured postnatal rat hippocampal neurons by blocking ionotropic quisqualate receptor desensitization. J Neurophysiol 68:1930-1938.

Thio LL, Clifford DB, Zorumski CF (1992b) Blockade of ionotropic quisqualate receptor desensitization by wheat germ agglutinin in cul- tured postnatal rat hippocampal neurons. J Neurophysiol 68:19171929.

Thio LL, Clifford DB, Zorumski CF (1993) Concanavalin A enhances excitator y synaptic transmission in cultured rat hippocampal neurons. Synapse 13:94-97.

Trussell LO, Fischbach GD (1989) Glutamate receptor desensitization and its role in synaptic transmission. Neuron 3:209-218.

Vyklicky L Jr, Patneau DK, Mayer ML (1991) Modulation of excitatory synaptic transmission by drugs that reduce desensitization at AMPA/Kainate receptors. Neuron 7:971-984.

Wyllie DJA, Traynelis SF, Cull-Candy SG (1993) Evidence for more than one type of non-NMDA receptor in outside-out patches from cerebellar granule cells of the rat. J Physiol (Lond), in press.

Yamada KA, Rothman SM (1992) Diazoxide blocks glutamate desensitization and prolongs excitatory postsynaptic currents in rat hippocampal neurons. J Physiol (Lond) 458:385-407.

Younkin DP, Tang C-M, Hardy M, Reddy UR, Pleasure S, Lee VMY, Pleasure D (1993) Inducible expression of neuronal glutamate receptor-channels in the NT2 human cell line. Proc Natl Acad Sci USA 90:2174-2178.

Zorumski CF, Yamada KA, Price MT, Olney JW (1993) A benzodiazepine recognition site associated with the non-NMDA glutamate receptor. Neuron 10:61-67. 